\title{
Construção de um pêndulo com ímã e bobina destinado ao ensino do eletromagnetismo
}

\author{
Alisson Cristian Giacomelli ${ }^{1}$ \\ Universidade de Passo Fundo \\ Carlos Juarez Souza da Silva ${ }^{1}$ \\ Graduado em Física - Licenciatura \\ Cleci Teresinha Werner da Rosa ${ }^{1}$ \\ Universidade de Passo Fundo \\ Passo Fundo - RS
}

\section{Resumo}

Este artigo tem como objetivo descrever a construção de um equipamento didático, com base em materiais de fácil obtenção $e$ manipulação, que pode ser utilizado no ensino de fenômenos relacionados à Lei de Faraday-Lenz. O dispositivo foi denominado de Pêndulo Indutor e constitui-se de um ímã que oscila sobre uma bobina. LEDs ligados à bobina auxiliam na percepção da tensão induzida, bem como na visualização dos diferentes sentidos da corrente. Trata-se de uma montagem simples e de baixo custo que poderá ser reproduzida nas escolas de ensino médio para o uso em atividades experimentais. Ao longo do texto, são apresentados os passos para a construção do dispositivo e são fornecidas sugestões para sua utilização. Por meio deste artigo, espera-se contribuir para a área de Ensino de Física, apresentando uma alternativa para a abordagem da Lei de FaradayLenz.

Palavras-chave: Pêndulo; Ímã; Bobina; Experimentos de Física; Eletromagnetismo.

\footnotetext{
${ }^{+}$Construction of a pendulum with magnet and coil intended for the education of electromagnetism

* Recebido: outubro de 2019. Aceito: maio de 2020.

${ }^{1}$ E-mails: alissongiacomelli@upf.br; 54@upf.br; cwerner@upf.br
} 


\begin{abstract}
This article aims to describe the construction of didactic equipment, based on materials that are easy to obtain and manipulate, that can be used to teach phenomena related to the Faraday-Lenz Law. The device was called the Inductor Pendulum and consists of a magnet that oscillates on a coil. LEDs connected to the coil assist in the perception of the induced voltage, as well as in the visualization of the different directions of the current. It is a simple and low cost assembly, which can be reproduced in high schools for use in experimental activities. Throughout the text, the steps to build the device are presented, as well as suggestions for its use. Through this article it is expected to contribute to the area of Physics Education by presenting an alternative to the Faraday-Lenz Law approach.
\end{abstract}

Keywords: Pendulum; Magnet; Coil; Physics Experiments; Electromagnetism.

\title{
I. Introdução
}

A Física é incorporada à cultura e integrada aos instrumentos tecnológicos que cercam o cotidiano doméstico, social e profissional, tornando-se indispensável à formação da cidadania contemporânea. Nesse contexto, ensinar Ciências na atualidade é uma tarefa que exige habilidades e um constante aprimoramento profissional. Assim, surgem inúmeras estratégias didáticas, tais como as atividades experimentais, que, aliadas às discussões teóricas, podem promover uma melhoria no ensino de Física (NEVES, 2015).

Pode-se dizer que a experimentação tem a capacidade de despertar o interesse dos alunos, permitindo proporcionar uma melhoria no processo de aprendizagem, por meio de reflexões, discussões, elaboração de hipóteses, contextualização do conhecimento, entre outros aspectos que são inerentes e possíveis de se contemplar nesse tipo de atividade. Nesse sentido, na condição de ferramenta didática, os experimentos desempenham um papel relevante no aprendizado dos conteúdos de Física, especialmente na compreensão de conceitos mais abstratos ou mais distantes da realidade dos alunos (ROSA, 2014).

Tal afirmação é corroborada pelos Parâmetros Curriculares Nacionais (PCNs+), ao enfatizarem a importância das atividades experimentais no ensino de Física:

$E$ É indispensável que a experimentação esteja sempre presente ao longo de todo o processo de desenvolvimento das competências em Física, privilegiando-se o fazer, manusear, operar, agir, em diferentes formas e niveis. É dessa forma que se pode garantir a construção do conhecimento pelo próprio aluno, desenvolvendo sua 
curiosidade e o hábito de sempre indagar, evitando a aquisição do conhecimento científico como uma verdade estabelecida e inquestionável (BRASIL, 2002, p. 84).

Considerando, por um lado, que o uso de atividades experimentais pode contribuir para a aprendizagem dos estudantes e, por outro, a realidade da maior parte das escolas públicas, que não dispõem de recursos para o acesso a equipamentos sofisticados, "recorrer à construção de equipamentos simples com materiais de fácil aquisição e reposição passa a ser uma alternativa para agregar a experimentação ao ensino, de modo a torná-la um instrumento à disposição e ao alcance do professor" (DARROZ; ROSA; ROSA, 2016, p. 19).

Conforme Hodson (1988), se forem abordados como alternativa metodológica, visando se tornar uma ferramenta para o ensino, e não um equipamento para desenvolver teorias, os experimentos podem estimular a autoestima e a confiança do aluno, demonstrar o poder da previsão teórica dos conteúdos e, ainda, ensinar algo sobre a natureza do conhecimento científico. Além disso, segundo Rosa et al. (2013, p. 84), "as atividades experimentais possibilitam a vivência de uma Física mais prazerosa, mais intrigante, mais desafiadora e imbuída de significados".

Desse modo, a utilização de atividades experimentais nas aulas de Física revela-se como um recurso capaz de estimular os estudantes, despertar sua curiosidade, romper a sequência de aulas tradicionais, possibilitando que o sujeito se mostre ativo no processo de ensino, ao proporcionar o envolvimento e a troca de saberes. Assim, destaca-se que o seu uso pode favorecer a criação de um ambiente capaz de despertar o interesse do educando pela Ciência, ajudando-o a superar as dificuldades encontradas e a entender conteúdos mais abstratos, como, por exemplo, os tópicos relacionados ao eletromagnetismo.

Conforme Zanardi, Soga e Muramatsu (2012), a Lei de Faraday-Lenz é comumente tomada pelos estudantes como um conteúdo difícil dentre os abordados no ensino médio. Segundo o autor, por esse motivo, o tema é, muitas vezes, deixado de lado pelo professor, que prioriza outros assuntos dentro da vasta programação curricular existente nesse nível de escolaridade. A partir desses pressupostos, o presente trabalho propõe a construção de um dispositivo de fácil execução e operação, que pode ser utilizado na realização de atividades experimentais relacionadas ao eletromagnetismo em nível de ensino médio. Diante disso, busca-se acrescentar uma contribuição às muitas outras que abordam atividades experimentais para o ensino da Lei de Faraday-Lenz, como é o caso dos trabalhos de Pimentel e Zumpano (2008), Paula e Vianna (2007), Laia et al. (2017) e Souza, Silva e Balthazar (2019).

A fim de atender aos objetivos apontados, o presente texto relata, inicialmente, o processo de construção do instrumental, denominado de Pêndulo Indutor, descrevendo os materiais e procedimentos utilizados no dispositivo. Na sequência, apresenta propostas de uso do equipamento, relacionadas à abordagem das Leis de Faraday e Lenz, no contexto da Física do ensino médio, expondo resultados e discussões acerca da sua utilização. 


\section{Construção do equipamento}

Com o objetivo de ofertar aos educadores das instituições de educação básica equipamentos acessíveis e de fácil construção, descrevem-se, a seguir, os materiais utilizados e os procedimentos adotados para a construção do dispositivo.

A Fig. 1 mostra uma fotografia do Pêndulo Indutor pronto para uso, ressaltando-se que as dimensões aqui apresentadas são apenas sugestivas, podendo, portanto, ser modificadas.

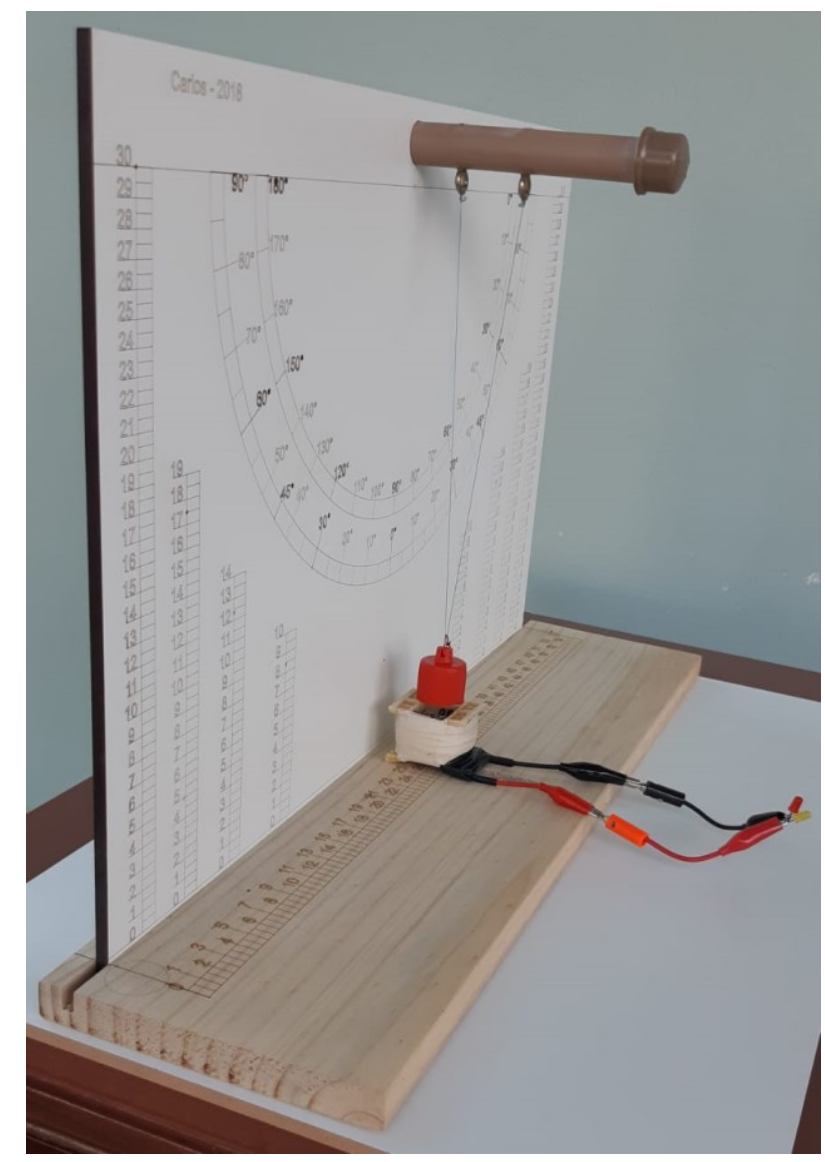

Fig. 1 - Vista do Pêndulo Indutor. Fonte: acervo pessoal, 2019.

Para o suporte vertical do pêndulo, foi utilizada uma chapa de MDF, com revestimento branco liso nas duas faces, medindo $35 \mathrm{~cm}$ de altura por $55 \mathrm{~cm}$ de comprimento e 0,6 cm de espessura (Fig. 2). Sobre a chapa de MDF, foram gravados, a laser, os desenhos das linhas, dos semicírculos graduados (semelhante a um transferidor), das réguas e do orifício na parte superior central.

Os desenhos foram feitos no CorelDRAW ${ }^{\circledR}$ (outra opção é o AutoCAD ${ }^{\circledR}$ ), programa de desenho gráfico compatível com a máquina de gravação a laser utilizada no projeto. Caso não se tenha acesso a uma máquina de gravação a laser, pode-se imprimir o desenho em uma folha de papel com as dimensões adequadas e colá-la sobre a placa de MDF. As setas 
adicionadas na Fig. 2 servem para dar uma noção acerca das dimensões do desenho, tendo as duas setas de $25 \mathrm{~cm}$ a função de mostrar o comprimento do pêndulo em duas possíveis posições de seu movimento.

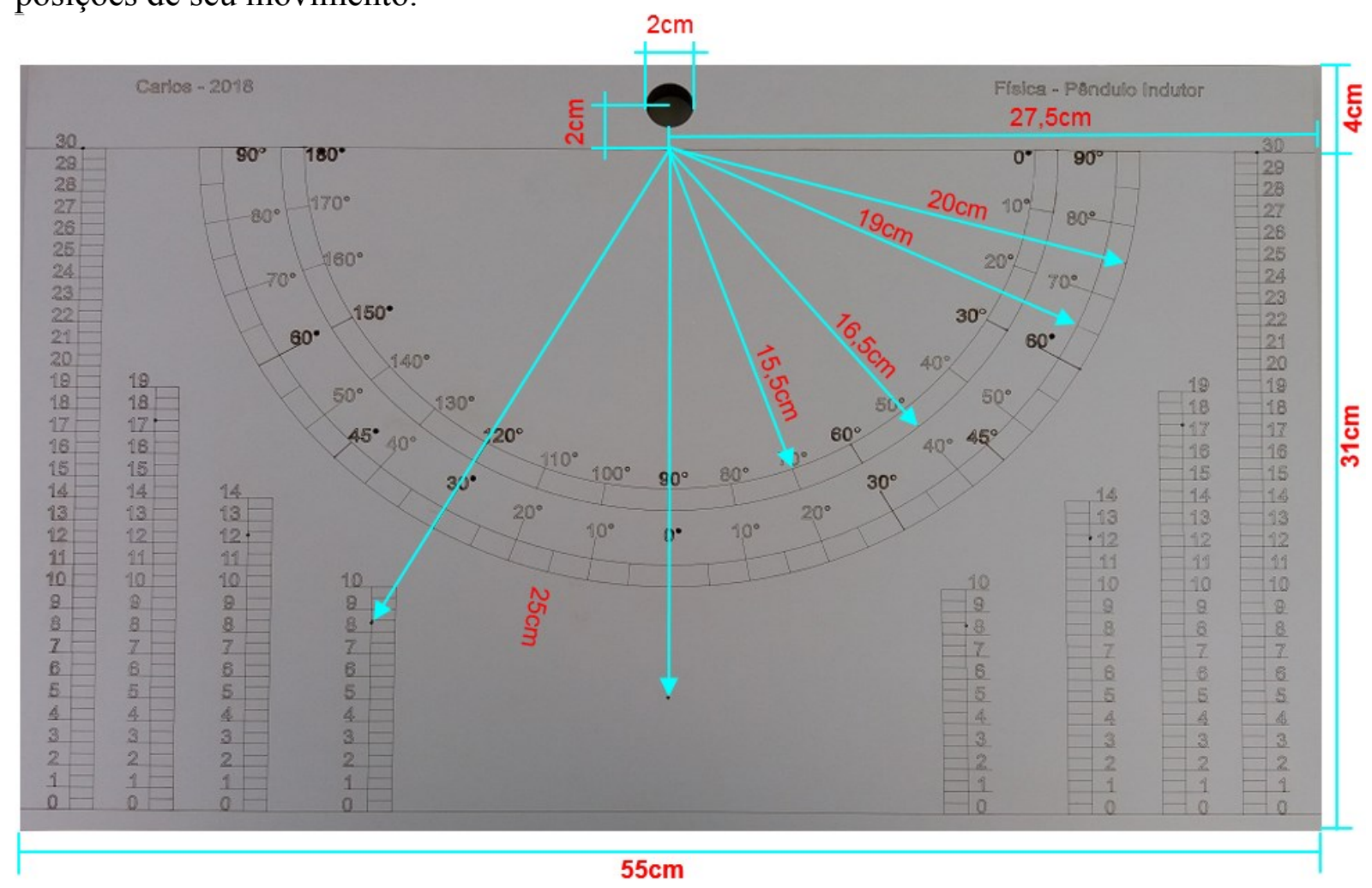

Fig. 2 - Suporte vertical do Pêndulo em MDF com as dimensões dos desenhos.

Fonte: acervo pessoal, 2019.

A base do pêndulo foi construída com uma peça de madeira maciça de $15 \mathrm{~cm}$ x 60 $\mathrm{cm} \times 1,7 \mathrm{~cm}$. Sobre essa base, foi gravada, também a laser, uma régua de $55 \mathrm{~cm}$ (Fig. 1). Com uma serra circular, foi feito um sulco (no sentido longitudinal) a uma distância de $1 \mathrm{~cm}$ da borda, com profundidade de $1 \mathrm{~cm}$, onde foi encaixado o suporte vertical do pêndulo, conforme ilustra a Fig. 1. Por fim, ressalta-se que o suporte vertical não foi fixado à base por meio de parafusos, porque, entre outros inconvenientes, estes poderiam desviar a trajetória do pêndulo.

O passo seguinte consiste em montar o pêndulo propriamente dito, que é composto de dois fios de nylon, de um ímã de neodímio com formato cilíndrico de $2,5 \mathrm{~cm}$ de diâmetro e 2,0 cm de altura, de uma tampa plástica (retirada de um frasco de óleo de máquina) e de um gancho metálico. Para construir o suporte horizontal, foi utilizado um pedaço de tubo PVC 20 $\mathrm{mm}$ com $15 \mathrm{~cm}$ de comprimento (Fig. 3). Nessa peça (suporte de PVC), foram fixados dois ganchos metálicos de $3,0 \mathrm{~cm}$ de comprimento para amarrar os fios de nylon do pêndulo, conforme ilustra a Fig. 3. Cabe salientar que é importante que o ímã tenha as dimensões anteriormente especificadas, pois o seu campo magnético deve ser muito intenso. Ímãs de 
neodímio menores, ou ímãs de ferrite, provavelmente, não serão suficientes para acender o LED.

Ainda, sobre o conjunto tampa/ímã/gancho (com massa de $70 \mathrm{~g}$ ), ressalta-se que foi necessário retirar a rosca da tampa plástica para o encaixe do ímã em seu interior (a tampa serve, também, de capa protetora para o ímã). Além disso, para fazer o gancho colocado em um orifício no "bico" da tampa (onde foi amarrado o fio de nylon), foi necessário dobrar um pedaço de fio de cobre esmaltado, como mostra a Fig. 3. Assim, após ser montado, o conjunto suporte horizontal/pêndulo foi encaixado no orifício central existente na parte superior do suporte vertical do dispositivo, de acordo com a Fig. 1.

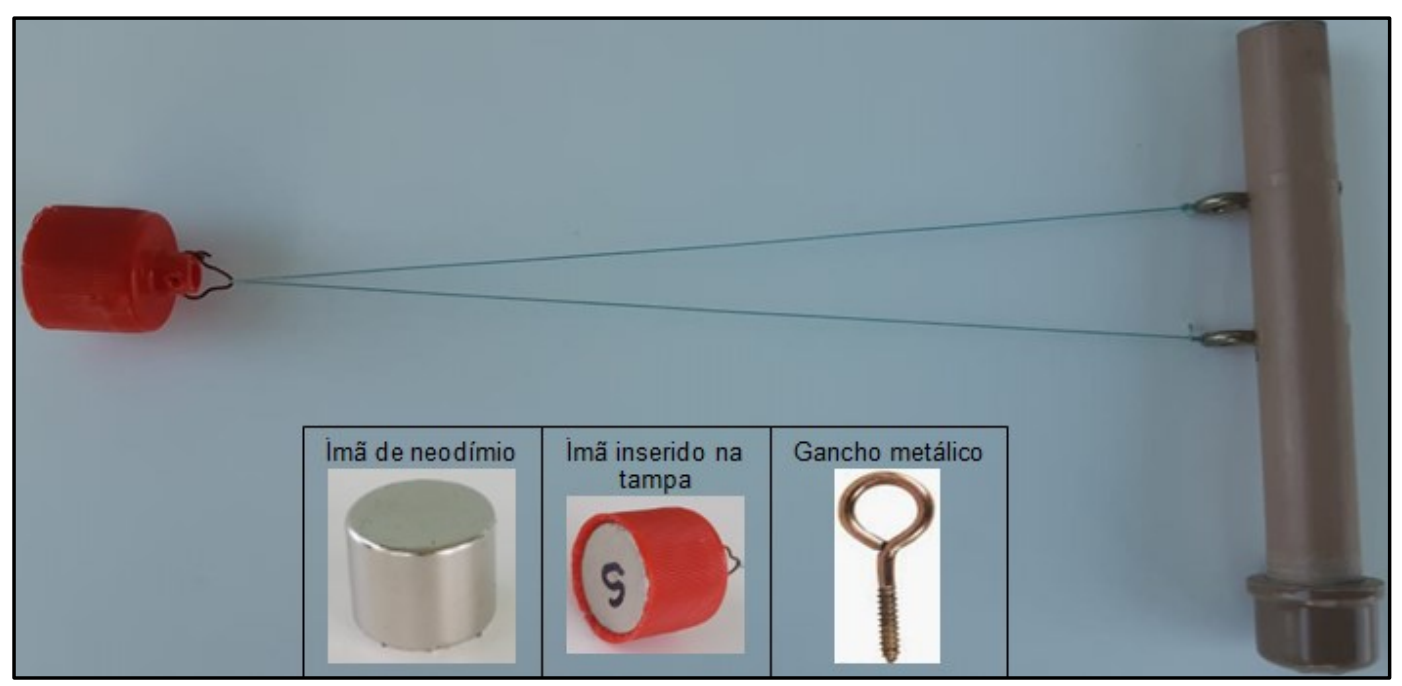

Fig. 3 - Suporte horizontal em PVC com o pêndulo e detalhes do ímã de neodímio, da tampa com o ímã inserido em seu interior e do um gancho semelhante aos fixados no PVC.

Fonte: acervo pessoal, 2019.

Em virtude do peso do suporte do pêndulo e da pequena espessura do suporte vertical de MDF, foi necessário colar uma peça de MDF extra (com um orifício, também, de $20 \mathrm{~mm}$ de diâmetro), como reforço, na parte de trás do furo de encaixe do suporte, conforme ilustrado na Fig. 4.

O passo final para a conclusão do Pêndulo Indutor (Fig. 1) consistiu na construção da bobina (no caso, um carretel de plástico, retirado de um transformador pequeno, envolto por fio de cobre), seguida da colocação dos conectores (terminais) e dos LEDs. Sendo assim, a bobina (Fig. 5) foi construída manualmente, com $251 \mathrm{~m}$ de fio de cobre esmaltado $\mathrm{n}^{\mathrm{o}} 30$ AWG, com diâmetro de $0,255 \mathrm{~mm}$, adquirido no Mercado Livre, dispostos em volta de um carretel com dimensões de $4 \mathrm{~cm}$ x $5 \mathrm{~cm}$, totalizando 2.300 voltas. 


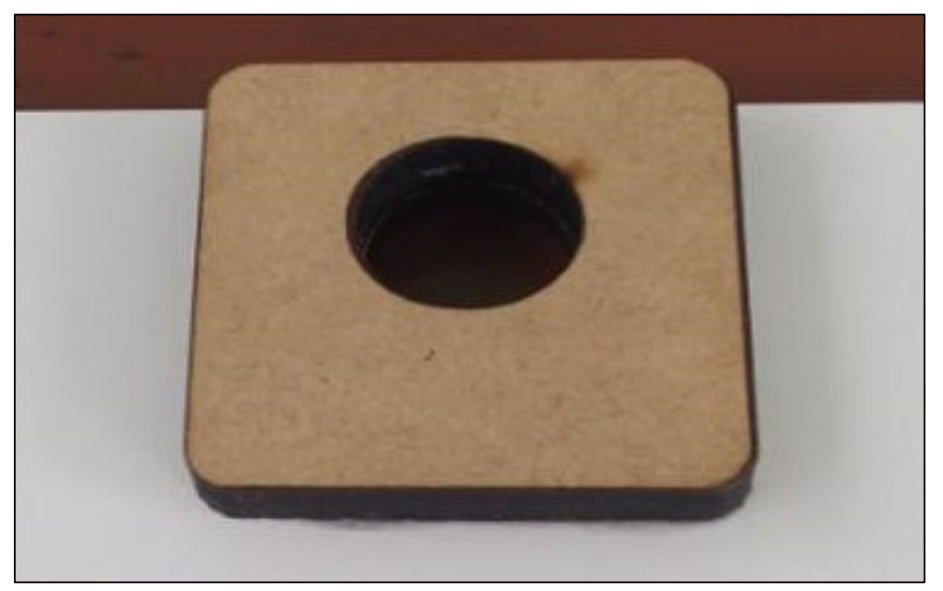

Fig. 4 - Detalhe do reforço no orificio do suporte vertical.

Fonte: acervo pessoal, 2019.

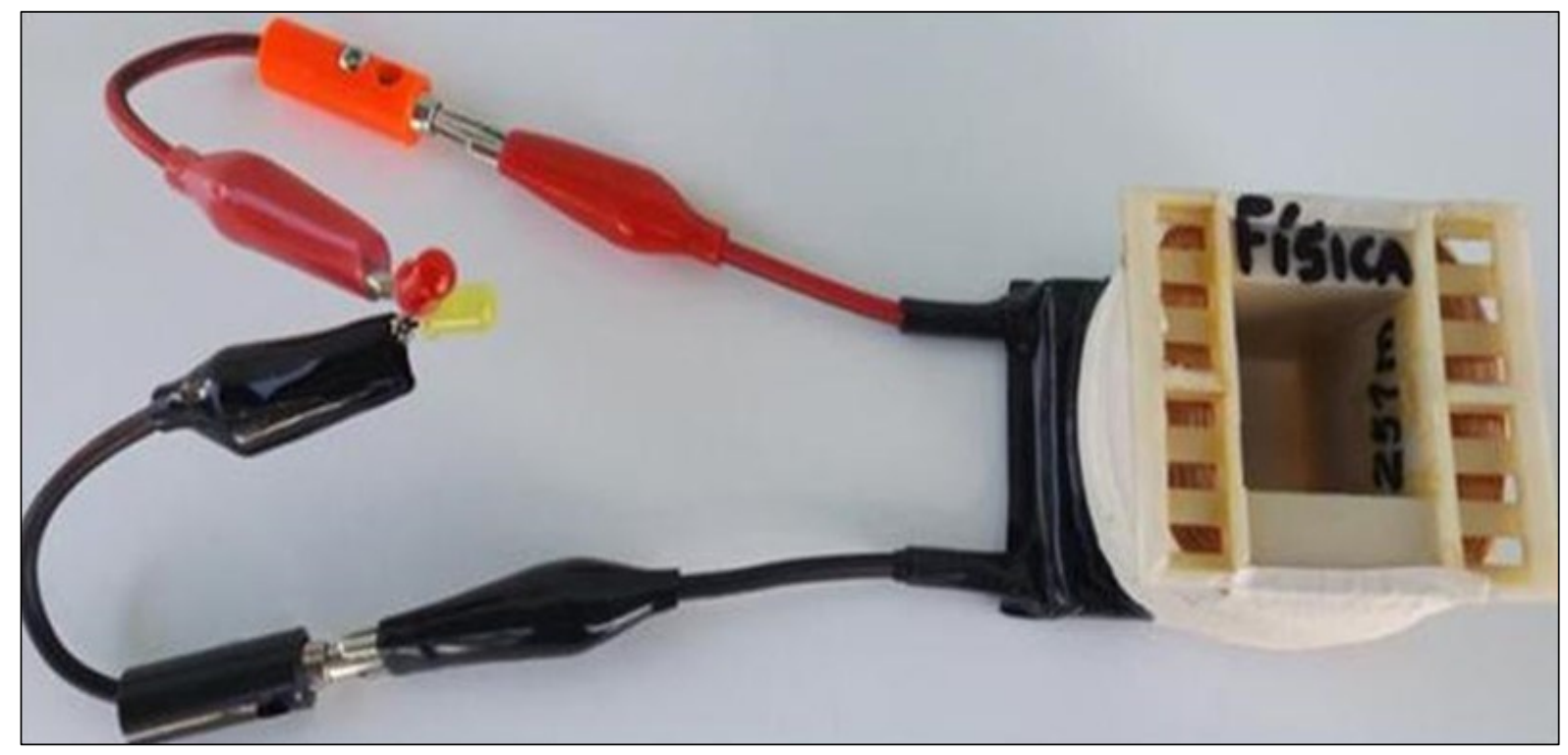

Fig. 5 - Detalhes do conjunto bobina/fios/conectores/lâmpadas LED.

Fonte: acervo pessoal, 2019.

Após essa etapa, foram fixados fios, com conectores nas pontas, nos dois terminais do enrolamento da bobina. Para a conclusão do conjunto apresentado na Fig. 5, foram presos, através de conectores (tipo clips jacaré), dois LEDs, como mostra a Fig. 6. O circuito foi montado de forma que, para um determinado sentido da corrente, ocorra o acendimento de somente um dos LEDs e, obviamente, ao se inverter o sentido da corrente, haja a inversão dos LEDs, acendendo o outro. A Fig. 6 mostra o esquema do circuito montado para o nosso arranjo. 


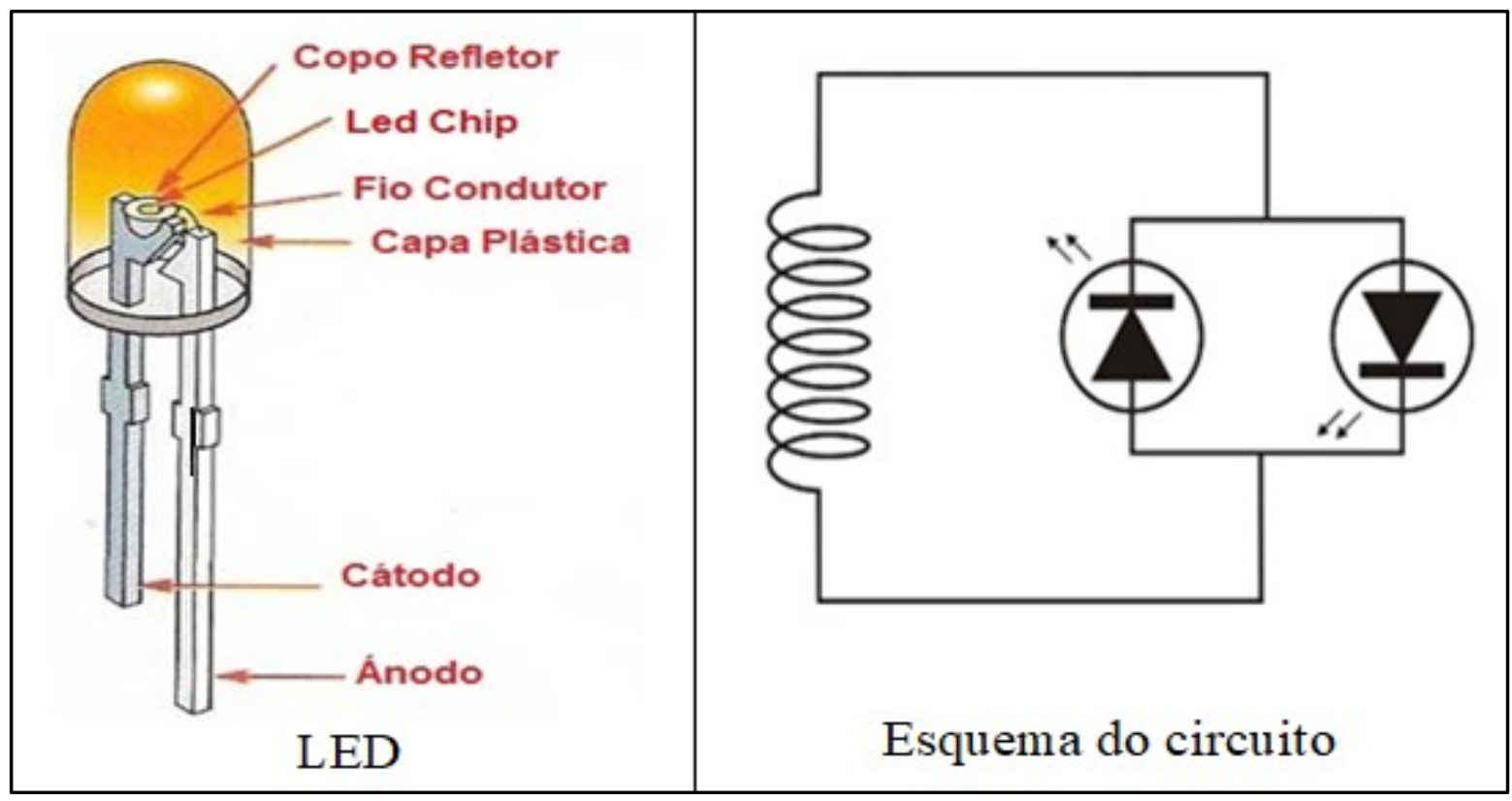

Fig. 6-Detalhes do LED e o esquema do circuito usado.

Fonte: acervo pessoal, 2019.

Por fim, cabe ressaltar que a distância entre o carretel da bobina e o conjunto tampa/ímã deve ser em torno de $5 \mathrm{~mm}$, conforme ilustra a Fig. 1. Em distâncias maiores, a variação do campo magnético do ímã poderá não induzir na bobina uma tensão elétrica suficiente para acender o LED.

\section{Sugestão de uso do equipamento}

Apresentam-se, a seguir, propostas de uso do equipamento para se abordar a Lei de Faraday-Lenz. Nesse sentido, o texto limita-se a descrever os procedimentos e os equipamentos utilizados, bem como os resultados obtidos na realização dos testes experimentais referentes às leis citadas. A elaboração de um roteiro didático para ser conduzido com os alunos fica sob a responsabilidade do educador, que poderá fazê-lo do modo que melhor se adapte às suas concepções pedagógicas. Em cada item, será apresentada uma breve discussão acerca das referidas leis, seguida da proposta de utilização do equipamento.

\section{III.1 Lei de Faraday}

De acordo com a Lei de Faraday (equação 1) ou Lei de Indução Eletromagnética, pode-se afirmar que o módulo da força eletromotriz induzida em uma espira condutora é igual à taxa de variação do fluxo magnético que atravessa a espira em função do tempo:

$$
\epsilon=-\frac{d \Phi_{B}}{d t}
$$


onde $\epsilon$ é a força eletromotriz induzida dada em volts e $\frac{d \Phi_{B}}{d t}$ é a taxa de variação do fluxo magnético $\Phi_{B}$ em função do tempo t. O sinal negativo no lado direito da igualdade remete à Lei de Lenz, que será abordada no próximo item, seguindo a sequência de experimentos propostos por meio da utilização do equipamento.

Como o experimento será realizado com uma bobina de $\mathrm{N}$ espiras, então, a variação do fluxo magnético em função do tempo irá induzir uma força eletromotriz em cada espira. Nesse sentido, a força eletromotriz induzida na bobina como um todo será a soma de cada uma dessas forças eletromotrizes. Se as espiras estiverem todas muito próximas umas das outras, ou seja, se a bobina for construída por meio de um enrolamento compacto, a força eletromotriz total induzida poderá ser obtida pela equação 2 , obtida quando se faz a equação 1 vezes o número de espiras $\mathrm{N}$ da bobina.

$$
\mathrm{C}=-\mathrm{N} \frac{d \Phi_{B}}{d t}
$$

De acordo com a equação 1, para que se induza uma força eletromotriz em uma determinada espira condutora, é necessário que se faça variar o fluxo magnético que a atravessa. Supondo uma espira plana atravessada perpendicularmente por um campo magnético uniforme, a equação para o fluxo magnético pode ser escrita da seguinte forma:

$$
\Phi_{B}=B A
$$

onde $\Phi_{B}$ é o fluxo magnético dado no sistema internacional em $\mathrm{Tm}^{2}$, B é a intensidade do campo magnético, A é a área da espira e $\Phi_{B}$ é o fluxo magnético dado no sistema internacional em $\mathrm{Tm}^{2}$. Com base na equação 3, para se variar o fluxo magnético que atravessa uma espira, pode-se fazer variar a sua área ou a intensidade do campo magnético que a atravessa.

\section{Primeira atividade experimental}

A atividade visa abordar experimentalmente a Lei de Faraday, utilizando a força eletromotriz induzida para acender os LEDs conectados aos terminais da bobina. Ela também possibilita, por meio da diferença no brilho dos LEDs, evidenciar o aumento da força eletromotriz induzida em relação ao aumento da taxa de variação do fluxo magnético em função do tempo sobre o condutor.

Conforme já mencionado, para variar o fluxo magnético que atravessa a bobina, pode-se variar a sua área ou a intensidade do campo magnético. Nesse caso, será variada a intensidade do campo magnético por meio da aproximação e do afastamento do ímã em relação ao condutor. A atividade consiste em elevar o conjunto tampa/ímã do pêndulo, sucessivamente, até as posições $30^{\circ}, 45^{\circ}$ e $60^{\circ}$, largando-o em seguida, para que oscile sobre a bobina a partir de cada posição. Feito isso, observa-se e compara-se o acendimento e o brilho dos LEDs durante o movimento oscilatório do pêndulo. Pode-se facilmente perceber que o brilho aumenta à medida que se aumenta o ângulo em que o pêndulo é abandonado. Isso 
ocorre porque, quanto maior o ângulo de abandono do pêndulo, maior será a variação do fluxo magnético e, consequentemente, de acordo com a Lei de Faraday, maior será a força eletromotriz induzida, bem como a corrente induzida, o que resultará na diferença de brilho dos LEDs.

Outra opção para evidenciar a Lei de Faraday por meio desse experimento consiste na realização de medições da tensão elétrica induzida na bobina. Para tanto, pode-se utilizar um multímetro ligado em paralelo no circuito da bobina, o qual pode medir a tensão a partir de cada posição $\left(30^{\circ}, 45^{\circ}\right.$ e $\left.60^{\circ}\right)$ em que o pêndulo for solto. Assim, deixando o pêndulo realizar uma oscilação completa, após ser abandonado de cada uma das diferentes posições, anotam-se os maiores valores visualizados no medidor elétrico (cada oscilação gera quatro valores de tensão no multímetro, resultantes da aproximação e do afastamento do ímã em relação à bobina).

\section{III.2 Lei de Lenz}

Em 1834, pouco tempo depois de Faraday elaborar a Lei de Indução, o físico Heinrich Lenz propôs uma regra que ficou conhecida como Lei de Lenz. A contribuição dessa lei reside no fato de que, por meio dela, é possível determinar o sentido da corrente induzida em uma espira condutora. A Lei de Lenz pode ser enunciada da seguinte maneira: “A corrente induzida em uma espira tem um sentido tal que o campo magnético produzido pela corrente se opõe ao campo magnético que induz a corrente" (HALLIDAY et al., 2010, p. 262). A Fig. 7 (a) e (b) traz situações que podem ilustrar a Lei de Lenz:

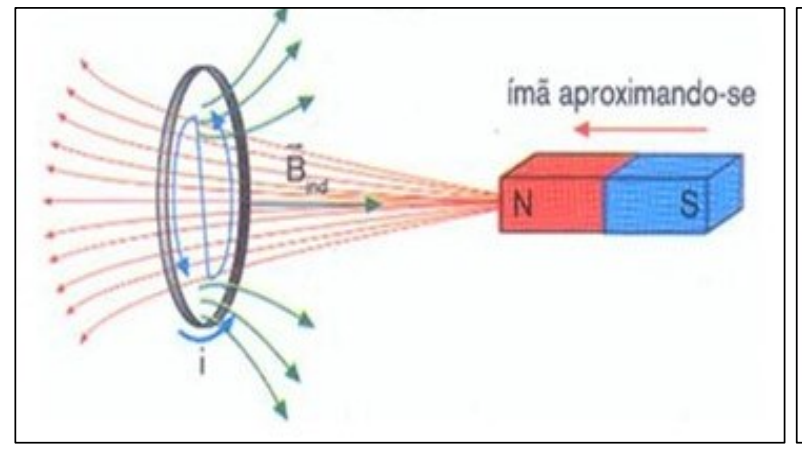

(a)

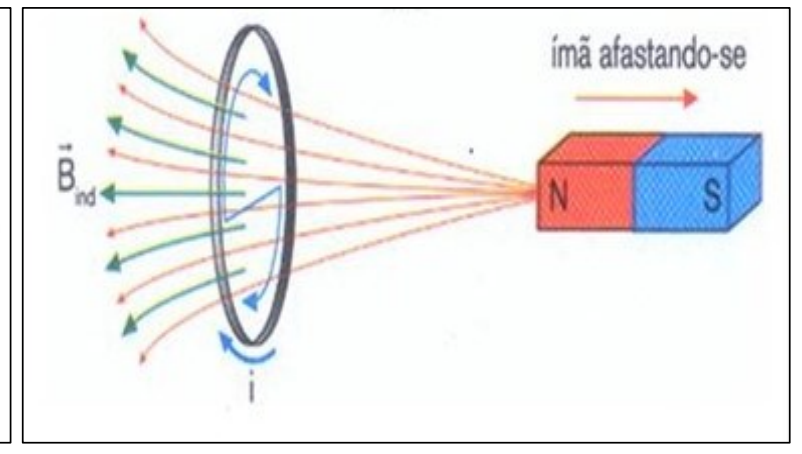

(b)

Fig. 7 (a) - Situação em que ocorre o aumento do fluxo magnético do ímã que atravessa a espira e o surgimento das linhas de indução do campo gerado (em sentido oposto ao do ímã) pela corrente induzida. (b) - O afastamento do ímã causa uma redução do fluxo magnético através da espira, e, opondo-se a essa redução, a corrente induzida cria um campo magnético no sentido do campo do ímã. Fonte: BONJORNO et al., 2016, p. 175.

Na Fig. 7(a), tem-se um ímã com seu polo norte se aproximando de uma espira condutora. Essa aproximação gera uma variação do fluxo magnético que atravessa a espira em função do tempo. De acordo com a Lei de Faraday, tal variação gera uma força eletromotriz 
induzida na espira e, consequentemente, também uma corrente elétrica i. Por sua vez, essa corrente i gera um campo magnético, levando a que a espira se comporte como um eletroímã. Conforme a Lei de Lenz, o sentido da corrente (que é o mesmo da força eletromotriz) deve ser tal que esta gere um campo que se oponha ao campo indutor, no caso, o campo magnético do ímã. Ou seja, se existe um polo norte de determinado campo magnético se aproximando da espira, a corrente nela induzida terá um sentido tal que fará surgir um polo norte no sentido de repelir a aproximação. Já se o polo norte estiver se afastando, como no caso da Fig. 7(b), o sentido da corrente i na espira será tal que surgirá um polo sul no sentido de atrair o ímã. A mesma regra vale para o caso de o polo sul estar se aproximando ou afastando.

Como ilustrado pelo exemplo do ímã e da espira constante na Fig. 7(a) e (b), a Lei de Lenz tem como ideia central a de "oposição". Por isso, sua expressão matemática é o sinal negativo na Lei de Faraday (equação 1).

\section{Segunda atividade experimental}

Nesta atividade, o objetivo está em abordar fenômenos relacionados à Lei de Lenz. Para tanto, coloca-se o pêndulo para oscilar, a partir de uma posição definida $\left(30^{\circ}, 45^{\circ}\right.$ ou $60^{\circ}$ ), sem a bobina presente no arranjo. Com um cronômetro, registra-se o tempo que o pêndulo leva para cessar o seu movimento devido às forças dissipativas existentes no sistema.

Em seguida, repete-se o procedimento, abandonando o pêndulo a partir do mesmo ângulo, porém agora com a bobina presente no arranjo. Ao se realizar, com o auxílio de um cronômetro, a medida do tempo que o movimento do pêndulo leva para cessar nessa segunda situação, percebe-se que esse é significativamente menor que o observado com o arranjo anterior. Essa redução no tempo necessário para que o pêndulo pare de oscilar só pode ser explicada pela atuação de alguma força que não estava atuando quando a bobina não se encontrava no arranjo.

Tal resultado pode ser compreendido utilizando-se a Lei de Faraday-Lenz. Ou seja, conforme já mencionado, a força eletromotriz induzida na bobina devido à variação do fluxo magnético que a atravessa tem como resultado uma corrente induzida que, por sua vez, produz um campo magnético que se opõe ao campo indutor, no caso, o campo magnético do ímã (pêndulo). Essa oposição do campo magnético produzido na bobina gera uma oposição ao movimento, isto é, uma força magnética que, na aproximação, repele o ímã e, no afastamento, o atrai. Essa força magnética, de acordo com a segunda Lei de Newton, gera uma aceleração que faz o movimento do pêndulo cessar mais rapidamente do que se não houvesse a bobina no arranjo.

\section{Terceira atividade experimental}

Esta atividade tem como objetivo contemplar a mudança de sentido da corrente induzida na bobina quando o ímã se aproxima ou se afasta dela. Sendo assim, para realizar a atividade, deve-se posicionar a mão sobre a bobina, conforme mostra a Fig. 8(a), de modo a 
parar o pêndulo sobre ela, quando ele for abandonado de certo ângulo $\left(30^{\circ}, 45^{\circ}\right.$ ou $\left.60^{\circ}\right)$. Com essa configuração, é possível observar o sentido da corrente induzida quando o polo do ímã se aproxima da bobina. Chega-se a essa conclusão pelo fato de ocorrer apenas o acendimento de um dos LEDs, nesse caso, o de cor vermelha.

Em seguida, com o conjunto tampa/ímã em repouso sobre a bobina - Fig. 8(b) -, deve-se dar um "empurrão brusco" no conjunto, de forma a afastá-lo dela. Nessa situação, percebe-se que o sentido da corrente induzida é contrário ao do evento anterior, tendo em vista que agora é o outro LED, o de cor amarela, que acende.

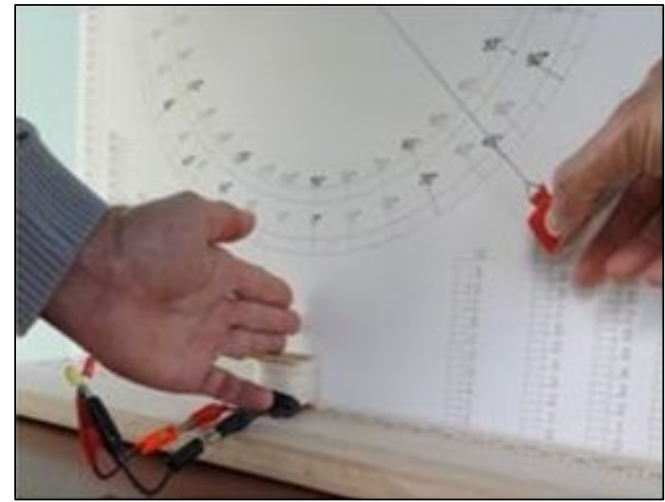

(a)

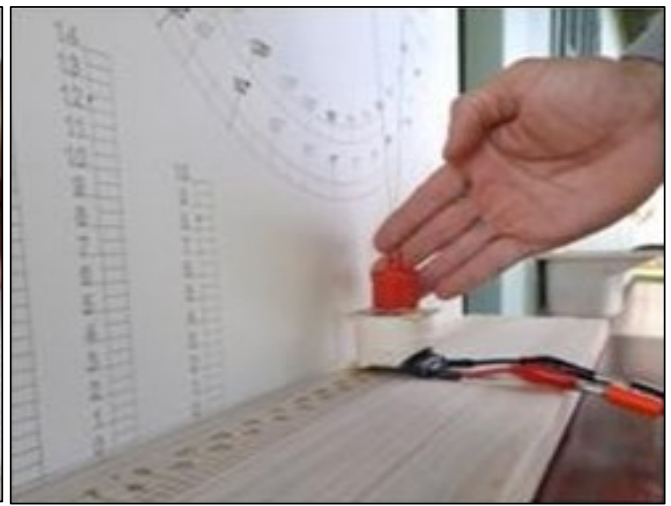

(b)

Fig. 8 (a) - Detalhe da posição da mão sobre a bobina. (b) - Posição da mão no momento do "empurrão" no pêndulo, de forma a afastá-lo da bobina.

Com esses procedimentos, é possível ilustrar de forma visual a Lei de Lenz. Obviamente que, se o professor dispuser de um amperímetro de ponteiro, poderá chegar à mesma conclusão com base no sentido de rotação do ponteiro. Todavia, no arranjo apresentado, optou-se por não utilizar qualquer dispositivo que pudesse oferecer um custo muito elevado para a construção e execução do experimento.

\section{Resultados e discussões}

Após o planejamento, a construção e a execução do experimento, é possível fazer algumas inferências acerca dos resultados obtidos. No que diz respeito à construção, cabe destacar que esta não envolve custo elevado e que os materiais são de fácil aquisição e manipulação, sendo possível adaptá-los de acordo com a disponibilidade e a habilidade no manuseio de ferramentas e na execução dos procedimentos referentes a essa etapa.

Sobre o primeiro experimento realizado, salienta-se que foi possível observar o fenômeno de indução eletromagnética por meio do acendimento dos LEDs. A atividade também permitiu observar com certa facilidade o aumento do brilho dos LEDs à medida que se aumentava o ângulo de abandono do pêndulo. Tais visualizações remetem à Lei de 
Faraday, que pode ser facilmente abordada por meio da primeira atividade sugerida neste artigo.

Realizando algumas medições com o uso de um voltímetro, foi possível verificar o aumento da tensão induzida em relação ao aumento da taxa de variação do fluxo no tempo sobre a bobina condutora, decorrente do fato de que se forneceu mais energia mecânica ao sistema a partir do aumento de cada uma das posições $\left(30^{\circ}, 45^{\circ}\right.$ e $\left.60^{\circ}\right)$ em que o pêndulo foi solto. Foram realizadas medições para cada um dos ângulos, e os valores obtidos estão dispostos na Tabela 1.

Tabela 1 - Resultados obtidos a partir das diferentes posições do conjunto tampa/ímã.

\begin{tabular}{c|c}
\hline $\begin{array}{c}\text { Posição de abandono do pêndulo } \\
\text { (ângulo) }\end{array}$ & Maior tensão medida \\
\hline $30^{0}$ & $0,8 \mathrm{~V}$ \\
\hline $45^{0}$ & $0,9 \mathrm{~V}$ \\
\hline $60^{0}$ & $1,1 \mathrm{~V}$ \\
\hline
\end{tabular}

Fonte: dados da pesquisa, 2019.

Sobre a segunda atividade experimental, uma vez executada a proposta, e comparando-se os dois movimentos, foi possível constatar uma redução no tempo necessário para cessar o movimento oscilatório do pêndulo quando a bobina estava presente. Esse resultado está diretamente relacionado com a Lei de Faraday-Lenz, e, apesar de não se ter realizado medições detalhadas da força magnética atuante no sistema, o efeito visual, por si só, já é bastante significativo.

Por fim, quanto ao terceiro experimento, executados os procedimentos previstos para a atividade, verificou-se que, quando o conjunto tampa/ímã se aproxima, somente um dos LEDs acende (o mesmo LED se acende independentemente do lado da bobina em que ocorre a aproximação). Já quando o conjunto se afasta, também por ambos os lados da bobina, somente o outro LED acende. Isso ocorre porque o LED só permite a passagem de corrente elétrica em um sentido. $\mathrm{O}$ fato de as correntes elétricas induzidas terem sentidos opostos na aproximação e no afastamento de um mesmo polo do ímã remete à Lei de Lenz, discutida anteriormente neste artigo.

\section{Considerações finais}

Cada vez mais, o mundo está repleto de tecnologias que são consequência de aplicações dos mais diversos conhecimentos científicos. Um deles é o eletromagnetismo, presente nos smartfones, televisores, computadores etc. Nesse sentido, é de fundamental importância pensar em estratégias que ofereçam alternativas capazes de facilitar o seu ensino 
em nível de educação básica. Partindo dessas identificações e das potencialidades do uso de atividades experimentais, brevemente apresentadas na introdução, o presente artigo mostrou a construção de um equipamento didático simples, denominado de Pêndulo Indutor, para abordar fenômenos físicos relacionados à Lei de Faraday-Lenz. Alguns desses fenômenos foram apresentados teoricamente e exemplificados por meio das atividades experimentais sugeridas no texto.

Para a construção do dispositivo, prezou-se pela utilização de materiais de fácil aquisição e manipulação, além de baixo custo final, para que possa ser reproduzido em diferentes contextos da educação básica. Ainda, considerou-se que é viável adequar o uso do equipamento, aprofundando ou modificando o foco da análise. Por exemplo, para um estudo posterior, seria possível utilizar aquisição de dados por meio de análise de vídeo, utilizando o software Tracker. Uma dessas possibilidades é visualizada no trabalho realizado por Souza, Silva e Balthazar (2019), onde os autores têm como foco de análise a frenagem de um pêndulo de alumínio ao atravessar um campo magnético gerado por um conjunto de ímãs de neodímio, buscando discutir o arrasto magnético e as correntes de Foucault.

Nos experimentos aqui relatados, priorizou-se a observação de efeitos mais visuais, o que não exclui a possibilidade de se realizar outros procedimentos com o mesmo arranjo que possam levar a discussões mais quantitativas. Nesse caso, além do Tracker, outros softwares poderiam ser adotados para a aquisição de dados. Por exemplo, o trabalho de Laia et al. (2017) propõe a utilização do software gratuito Audacity para um experimento de indução eletromagnética. Segundo os autores, ao realizar as medições do mesmo evento usando um osciloscópio, a diferença nos valores foi mínima, o que evidencia a potencialidade da adoção do software no lugar de um equipamento caro e muitas vezes inacessível às escolas.

Ao encerrar, destaca-se que o equipamento apresentado neste artigo demonstra potencialidades no sentido de trazer uma proposta de construção simples, de baixo custo e que promove efeitos visuais capazes de tornar o processo de ensino mais atrativo, instigando os alunos a aprender Física. O experimento também se mostrou bastante eclético, podendo ser adaptado e até mesmo incrementado com base em resultados de outros estudos existentes na área do Ensino de Física. Essa adaptação e/ou incrementação poderá servir para redirecionar o foco e a amplitude de conceitos passíveis de serem trabalhados por meio da utilização do equipamento.

\section{Referências}

BONJORNO, J. R. et al. Física: Eletromagnetismo - Física Moderna. 3. ed. São Paulo: FTD, 2016.

BORGES, D. Diodo Emissor de Luz - LED. FronteiraTec. 2013. Disponível em: $<$ http://fronteiratec.com/blog/diodo-emissor-de-luz-led/>. Acesso em: 20 mai. 2020. 
BRASIL. $P C N+$ Ensino Médio. Orientações educacionais complementares aos Parâmetros Curriculares Nacionais: ciências da natureza, matemática e suas tecnologias. Brasília: Ministério da Educação, Secretaria de Educação Básica, 2002.

DARROZ, L. M.; ROSA, C. T. W. da; ROSA, A. B. Experimentos simples para visualização dos fenômenos de difração e interferência da luz. Revista Thema, v. 13, n. 2, p. 18-26, 2016.

GONÇALVES FILHO, A.; TOSCANO, C. Física: interação e tecnologia. 2. ed. São Paulo: Leya, 2016. v. 3.

HALLIDAY, D. Fundamentos de Física: Eletromagnetismo. 10. ed. Rio de Janeiro: LTC, 2010. v. 3.

HODSON, D. Experiments in science and science teaching. Educational Philosophy and Theory, v. 20, n. 2, p. 53-66, 1988.

LAIA, A. S. et al. Uma prática experimental alternativa para o estudo quantitativo de indução eletromagnética no Ensino Médio. Experiências em Ensino de Ciências, v. 12, n. 5, p. 211 $222,2017$.

NEVES, J. H. M. Uso de experimentos, confeccionados com materiais alternativos, no processo de ensino e aprendizagem de Física: lei de Hooke. 2015. 57 f. Dissertação (Mestrado em Ensino de Física) - Universidade Estadual Paulista Júlio de Mesquita Filho, Presidente Prudente.

PAULA, A. G.; VIANNA, D. M. Levitação eletrodinâmica: o ensino de Física, baseado no enfoque CTS, na discussão para a melhoria da qualidade do ar. Física na Escola, v. 8, n. 1, p. 35-39, 2007.

PIMENTEL, J. R.; ZUMPANO, V. H. Demonstre em aula: correntes de Foucault exploradas com um disco rígido de computador. Caderno Brasileiro de Ensino de Física, v. 25, n. 1, p. 160-167, 2008.

ROSA, C. T. W. da. A experimentação como estratégia de ação no ensino de Física: da história às novas tendências. In: ROSA, C. T. W.; MARASINI, S. M.; MISTURA, C. M. Reflexões pedagógicas: cenários de iniciação à docência. Subprojetos Física - Matemática Química. Passo Fundo: Ed. Universidade de Passo Fundo, 2014. p. 19-23. 
ROSA, C. T. W. da et al. Atividade experimental para demonstração dos fenômenos da reflexão, refração e reflexão total. Rencima, v. 4, n. 1, p. 75-85, 2013.

SOUZA, P. V. S.; SILVA, C. J. V.; BALTHAZAR, W. F. O arrasto magnético e as correntes de Foucault: um experimento de baixo custo com vídeo-análise. Revista Brasileira de Ensino de Física, v. 41, n. 2, p. e20180257-12, 2019.

ZANARDI, D. C.; SOGA, D.; MURAMATSU, M. Medindo a massa de um ímã durante a sua queda. Caderno Brasileiro de Ensino de Física, v. 29, n. 2, p. 289-312, 2012. 